\title{
Salvatore Abbruzzese, Un moderno desiderio di Dio. Le ragioni del credere in Italia
}

Soveria Mannelli, Rubbettino, 2010, 301 p.

\section{Enzo Pace}

\section{OpenEdition} Journals

Édition électronique

URL : http://journals.openedition.org/assr/22966

DOI : $10.4000 /$ assr.22966

ISSN : 1777-5825

Éditeur

Éditions de l'EHESS

Édition imprimée

Date de publication : 31 décembre 2011

Pagination : 85

ISBN : 9782713223273

ISSN : 0335-5985

Référence électronique

Enzo Pace, «Salvatore Abbruzzese, Un moderno desiderio di Dio. Le ragioni del credere in Italia », Archives de sciences sociales des religions [En ligne], 156 | octobre-décembre 2011, document 156-1, mis en ligne le 14 février 2012, consulté le 21 septembre 2020. URL : http://journals.openedition.org/ assr/22966; DOI : https://doi.org/10.4000/assr.22966

Ce document a été généré automatiquement le 21 septembre 2020.

(ㄷ) Archives de sciences sociales des religions 


\title{
Salvatore Abbruzzese, Un moderno desiderio di Dio. Le ragioni del credere in Italia
}

Soveria Mannelli, Rubbettino, 2010, 301 p.

\author{
Enzo Pace
}

\section{RÉFÉRENCE}

Salvatore ABBRUZZESE, Un moderno desiderio di Dio. Le ragioni del credere in

ItaliaSoveria Mannelli, Rubbettino, 2010, 301 p.

1 Salvatore Abbruzzese a sans aucun doute écrit un livre à thèse, même s'il se présente comme la synthèse de l'itinéraire intellectuel de l'auteur, de son doctorat à l'EHESS jusqu'à son activité actuelle de recherche et d'enseignement en sociologie de la religion à l'université de Trente. Le texte reprend en effet trois étapes fondamentales de sa recherche: la sociologie de la vie consacrée, l'analyse des valeurs religieuses à la lumière de l'enquête longitudinale de l'EVS (enquête européenne sur les valeurs à laquelle il a participé à plusieurs reprises pour la partie italienne) et la réflexion théorique sur les formes modernes du croire religieux à une époque post-séculière.

2 Les thèmes mentionnés correspondent aux trois parties qui composent le livre et le fil conducteur qui les lie est évident: la religion ne disparaît pas dans la société sécularisée, elle se transforme et se montre capable de se réconcilier aujourd'hui avec la modernité. Les arguments apportés par l'auteur pour soutenir cette thèse sont ou de type historico-sociologique (en cohérence avec les enseignements de Jean Séguy) ou tirés de l'analyse statistique et sociale des recherches empiriques sur la religiosité en Italie sous une perspective européenne, ou encore basés sur la réflexion critique des paradigmes théoriques les plus connus du domaine des sciences sociales des religions.

3 L'ensemble converge pour montrer comment l'individu moderne peut trouver, en soi et dans le milieu social, de bonnes raisons pour croire tout en maintenant jalousement ses 
propres prérogatives d'homme moderne, c'est-à-dire une autonomie dans ses choix de croyance et un besoin de sens au sein d'une société toujours plus fragmentée. De cette manière la sensibilité religieuse, dont parle l'auteur - qui préfère cette notion à celle de religiosité, plus traditionnelle - ne rentre plus forcément en collision avec la sensibilité laïque (qui ne se nourrit donc pas de références à un système de croyances religieuses). $\mathrm{Au}$ contraire, le terrain des rencontres possibles s'élargit au fur et à mesure que la seconde sensibilité découvre qu'elle ne peut plus compter de manière certaine sur les valeurs historiques dont la modernité s'était faite porte-voix (le progrès, la libération confiée à la science et à la technologie, le déclin des sociétés du bien-être et ainsi de suite). Voilà donc quelle est la lueur qu'Abbruzzese aperçoit au sein de la société postséculière, où l'esprit de la sécularisation ne semble plus souffler avec autant de force que par le passé.

D'un point de vue théorique, la confrontation précise de l'auteur avec les thèses, respectivement de Weber et de Troeltsch, en référence à la fondation du moderne par rapport à la religion, et de Habermas, pour ce qui est de la discussion sur le postséculier, aurait pu être renforcée s'il s'était mesuré avec les thèses de Beck sur la société du risque. Quel est en effet le rôle de la religion dans la Risikogesellschaft (surtout dans ces sociétés autrefois radieuses et prospères de l'Occident)? Ne serait-ce pas que plus la ligne de fracture des sécurités sociales commence à s'élargir et plus les religions apparaissent comme une ressource communicative de sens, quand les autres systèmes idéologiques ne sont plus en mesure d'en offrir aux individus de la modernité avancée?

La lecture de la première partie est très prenante lorsque l'auteur analyse les espaces et les lieux où la mémoire religieuse chrétienne (dans le sens propre de cette notion réélaborée par Danièle Hervieu-Léger en référence à la religion) et les modèles alternatifs de vie religieuse sont encore visibles et donnent un sens (même au touriste religieux de passage qui se rend dans les sanctuaires et les monastères pour une rapide visite). Dans la deuxième partie, l'auteur reprend les résultats de certaines enquêtes nationales récentes qui ont été faites en Italie et au niveau européen (EVS) afin de montrer la bonne tenue de la religiosité en Italie, sans toutefois oublier comment l'individualisation du croire, même dans un pays à forte tradition catholique et avec une civilisation paroissiale encore bien vivante, peut aller s'accorder avec un sentiment diffus (romantique?) d'attachement à la mémoire religieuse catholique, au catholicisme en tant que code symbolique et représentation collective d'une identité nationale autrement précaire et incertaine. À ce propos toutefois, il aurait été utile de ne pas s'arrêter aux résultats de l'EVS de 1999 et surtout, il aurait été plus approprié de confronter les résultats de l'EVS avec d'autres recherches qui décrivent un paysage socioreligieux, tout au moins pour l'Italie, plus mouvementé et pas si différent des autres réalités sécularisées de l'Europe.

6 Voici donc un essai qui résume de manière appropriée les défis théoriques et méthodologiques avec lesquels la sociologie des religions contemporaines est appelée à se confronter. 